\title{
Analyzing Mathematical and Software Methods for Selecting and Designing Francis Turbine in Hydropower Plants
}

\author{
Moona Mohammadi, Mohammadreza Mohammadi, Alireza Mohammadi, and Said Farahat
}

\begin{abstract}
Some of the major hydropower plants calculations are turbine type selection, speed and diameter of runner, dimensions of draft tube and spiral case. Since manufacturers have their own professional softwares, educator and consultant engineers have to use commercial softwares or mathematical methods and rely on their results for estimation and preliminary studies.

This paper introduces result reliability of a commercial software that has special equations to calculate turbine, draft tube and spiral case, analyzing and comparing results with the mathematical method and actual values of six hydropower plants known as Maroon, Abbaspour II, Dez, Masjid Suleiman, Karkheh and Karun III located in Khuzestan Province, Iran. Comparing results of software and mathematical average errors with actual values indicated that only 6 parameters in software method and 4 parameters in mathematical method among 14 parameters have reliable results in Francis Turbine. These parameters are Runaway Speed, Runner Diameter, Shaft Diameter, A, D (spiral case parameters) and $\sigma$ (Thoma number) in software method and $\mathrm{B}, \mathrm{C}, \mathrm{E}$ (spiral case parameters) and $\sigma$ in mathematical method. Therefore it's not possible to confirm all parameters calculated with mathematical or software methods in Francis turbine.
\end{abstract}

Index Terms-Francis turbine, hydro turbine selection, turbnpro, mathematical method, software method.

\section{INTRODUCTION}

Although manufacturers have their own professional softwares for determining the final dimensions and exact estimation, one of the challenges of water power systems educators and consultant engineers in hydro power turbines is estimating parameters such as speed, runner diameter, dimensions of turbine, draft tube and spiral case in hydropower plants in order to utilize appropriate tools and

Manuscript received April 30, 2015; revised August 9, 2015. This work was supported in part by the Bushehr Gas Company and Khuzestan Water \& Power Authority. Authors take this opportunity to express a deep sense of gratitude to Standard and Research Office of Dam- Hydro Power Division of KWPA cordial support, valuable information and guidance, which helped them in completing this task through various stages.

Moona Mohammadi is with Khuzestan Water \& Power Authority, Ahvaz, Iran (e-mail: moona_mohammadi@yahoo.com).

Mohammad Reza Mohammadi was with University of Sistan and Baluchestan, Zahedan, 9816745639 Iran. He is now with the Bushehr Gas Company, National Iranian Gas Company, 75157-53174 Iran (tel.: +989166047873; e-mail: mhrz_mohammadi@yahoo.com.au).

Ali Reza Mohammadi is with University of Applied Science and Technology, Deylam, Iran (e-mail: aalirezamohammadi@gmail.com).

Said Farahat is with the Mechanical Engineering Department, University of Sistan and Baluchestan, Zahedan, 9816745639 Iran (e-mail: farahat@hamoon.usb.ac.ir). equations.

Researchers like de Siervo and de Leva attempted to find appropriate equations for estimating the dimensions of turbine. From 1960 to 1976, they studied Francis, Kaplan and Pelton turbines and they selected the best results and equations for these three turbines [1]-[4]. Schweiger and Gregori studied Kaplan turbine. This research provided special equations for calculating the runner diameter, Thoma number and suction head [5]. In 1989, Gordon researched about Francis turbine. This research provided equations for calculating of Thoma number and suction head [6]. In 1995, Harding introduced a method for cross- flow turbines to design and manufacture in Mini and micro Hydro Power Stations (MHPSs) [7]. These turbines are used in developing countries because of their low cost. On the other hand they have flexibility in use in wide range of flows and head which causes maximum efficiency. Regarding the importance of hydro power plants rehabilitation where some parts of machine are renewed and other parts are kept and repaired to improve efficiency and operating condition, some of the hydro's companies like VATECH upgrades and refurbishes Francis hydro power turbines. In 2001, VATECH used CFD designs to rehabilitate hydro power turbine. It causes modernization accomplishment in short time. Regarding high quality of manufacturing process is necessary for improving hydraulic quality and lift time of turbine; VATECH used NC focused on manufacturing and welding of the runner technology [8]. In 2006, Kyaw et al. designed runner diameter, bucket size and nozzle diameter of Pelton wheel. This calculation is based on the $500 \mathrm{~m}$ head, $750 \mathrm{rpm}$ shaft speed and $1.5 \mathrm{Mw}$ power output while quality of Pelton wheel, size of bearing and casing were not been considered [9]. In 2007, Hydraulic machinery research institute in Iran presented the Francis hydro turbine design process describing a function to estimate the runner perpendicular plan which decreases design process. Results have a good agreement with the usual method [10]. In 2010, Soni et al. used CFD tool to find optimum design of draft tube. Their assumption was based on a large amount of swirl in the draft tube inlet. By several arrangement and combination of different parts, an optimum design was achieved. This optimum design of several parts like suction head, elbow and exit diffuser guaranteed best pressure recovery, hydraulic efficiency of turbine unit and part load. Therefore by using CFD tool and improving various part of draft tube, the initial design was optimized [11]. In 2011, Albuquerque et al. have introduced a system for Francis turbines for optimization. The flow solver is based on streamline analysis. Several empirical correlations were used 
in this research. Optimization of turbine design was based on two different techniques coupled with the flow solver. While evaluating of Francis turbine performance and searching for optimum conceptual design were accomplished. Comparing set of variable design and operating point with the basic Francis turbine design, the performance improvement was demonstrated [12].

In 2013, Obrovsky et al. introduced designing process of high specific speed. This research was based on CFD method and had three main parts: 1) Optimizing the process of the runner design, 2) prediction of cavitation by using CFD model, 3) preliminary verification by using CFD model for the entire turbine unit. CFD analysis showed that in the maximum power output of the turbine, the efficiency was dependent on cavitation coefficient. The results showed that the discharge for the rated head of the turbine was dependent on mildly flat characteristic of the turbine [13].

In 2013, Nasir presented a complete design of cross-flow turbines. By choosing different values of head and flow rate, the maximum efficiency was obtained about $88 \%$. In this research design parameters such as runner diameter, runner length, water jet thickness, blade spacing, radius of blade curvature, turbine power, turbine speed and number of blades were determined for the maximum turbine efficiency [14]. In 2013, Odesola and Oririable designed a small scale Francis turbine runner. In this research, designed head and flow rate were $6 \mathrm{~m}$ and $0.244 \mathrm{~m}^{3} / \mathrm{s}$ respectively. Two commercial CFD code (ANSYS FLUENT and Solidworks Flow Simulation) were used to analyze the runner, stay vanes, guide vanes, spiral case and draft tube of Francis turbine. The research was based on 2D and 3D, steady state and singe-phase model. Based on available head and flow rate, the dimension of the runner was obtained, using empirical equations. Finally CFD analysis was used to optimized runner shape and performance. The performance was obtained at different opening of guide vane [15]. In 2013, Nasir used Matlab Simulink procedure to design micro-hydro-electric power plant. Several design parameters such as site survey, head and flow rate measuring; civil work components, hydraulic turbine type selection, turbine dimensions and specifications of electrical power generator were considered [16].

Many types of software have been designed for hydro turbine calculations since 1990s. It is important to mention that they do not give similar results; each software covers a part of consultant engineer's purposes. Hydra- HP is one of the most important softwares designed for hydro turbine calculations. The small hydro power potential at any given site can be estimated by this software. By using this software, hydrological surveys costs would be reduced. It can be used for preliminary design and selection of hydro turbine. The cell resolution of $1 \mathrm{~km}$ by $1 \mathrm{~km}$ grid is provided by this software. On the other hand the software contains a group of flow duration curves. Considering dependable flow, residual flow and hydraulic head, several parameters such as number of turbines and hydro power potential relating to given potential site can be calculated. Consequently the Hydra-HP provides the maximum generation of power and net generation of annual energy for a mentioned site. This software has Turbine Selection Module where the user can specify the design head and flow conditions for the sites. The software includes eight turbines: Pelton, Turgo, Cross Flow, Francis Open Flume, Francis Spiral Case, and Propeller. After introducing site conditions, the software compares input data with individual information to select the best turbine through eight key turbine types [17], [18]. The suitable software for evaluating small-scale hydroelectric power sites is IMP. The relevant meteorological and topographical data is used in this software. The software can provide power study, development of a flood frequency curve and fish habitat analysis. Generation the flood frequency curve can be provided by using topographic information of the site. Daily precipitation, maximum and minimum temperature and a description of the basin is defined in IMP. This information can be used to generate a continuous hourly or daily time series of stream flow in Watershed Model. Mountainous areas are the basis of watershed model. In non-mountainous areas, watershed model has not been used. By using Hydroelectric Power Simulation Model, the user can obtain the daily energy output for a run-of-river or reservoir storage. Hydrologic daily time series is also generated by the Watershed Model. A sensitivity analysis on the results of a simulation is accomplished. Then, using economic data, the optimal installed capacity is achieved. The weighted available area for one or more types of fish, in an especial cross- section of stream at an especial flow, is assigned in a Fish Habitat Analysis Model [19], [20]. The potential energy of accessible hydro power site located in USA would be estimated by HES software. The user can appoint environmental issues for potential hydropower sites. The software can assign acceptable factors for each site. These factors are based on the environmental issue that is preset. Then reports of these acceptable factors are generated [21], [22]. Retscreen can measure the potential energy of a small hydropower site (Small hydro, Mini hydro and Micro hydro). This software can also consider both run of river and reservoir hydropower plants. It is based on several worksheets: work sheets of energy model, hydrology analysis, load calculation, equipment data, cost analysis, analysis of greenhouse effects, providing a financial summary, analysis of risk, analysis of sensitivity and possibility of the plan, calculating efficiency, calculating plant capacity and creating power duration curve and calculating available energy. Some input data of this software include: topographic maps, load and flow duration curves, gross head, design discharge, peak load, energy demand rate, type of turbines and number of turbines. In this software, the design process is based on run of river plants and analysis of reservoir plants which requires some assumptions. Changes in gross head could not be simulated. Reservoir projects utilize the average head calculated without the software. The costs calculated by this software are 14 percent more than the actual costs [23].

10 different turbine configurations are covered by Turbine selection program. This program is used especially for low-head small hydro turbines. The user can introduce several data such as flow, desired number of units, head, system frequency, tail water level and operating pattern in hours per annum at each flow, as obtained from a flow-duration curve. Turbine selection program includes calculating of runner size and setting relative to tail water, speed and power output, providing turbine efficiency charts as a function of flow and power, the power plant output in $\mathrm{kWh}$ and the turbo-generator 
water-to-wire cost. These calculations are provided for 10 different turbine configurations. The limitations of the program are: power plant capacities up to about 30MW, turbine heads up to $30 \mathrm{~m}$ and maximum flow per turbine up to $200 \mathrm{~m}^{3} / \mathrm{s}$. Configurations of turbine- generator for all 10 generating units is achieved from manufacture's brochures [24]. VAPIDRO ASTE is a GIS integrated tool. This program includes calculating of the hydropower potential and identifies promising small scale hydro plants sites. In this program evaluation of water availability and management optimization is considered too by concerning head in the territory. The software includes other usages such as irrigation uses, drinkable water and existing hydropower plants. Cross section of river is divided to a hundreds sections. Considering minimum flow, the available discharges and potential hydropower production is calculated. Results of this software show, it is a strong tool to help user to decide about energy plan preparation [25].

TURBNPRO software is developed for estimating size and technical data in hydraulic turbines.

Input data of this software are: hydroelectric site conditions desired operating parameters and desired equipment arrangement. In details, input data include: unit discharge, rated net head, gross head and net head range, desired turbine centerline setting to tail water, system frequency $(50 \mathrm{~Hz}$ or 60 $\mathrm{Hz}$ ), efficiency priority, site elevation and water temperature. The user can obtain several output data such as size, speeds, setting limitations, dimensional and typical performance of turbine solutions, show performance in Hill Curve, cross plot or tabular formats, display graphical views of the turbine selection (spiral case, draft tube, runner diameter, shaft arrangement), present a briefing recommendation the advantages and disadvantages of the different type arrangement. TURBNPRO can also be used to calculate production of annual energy. This calculation is based on flow duration which is entered by user. The user can compare the obtained design parameters and produced energy of different turbine solutions. Afterwards the best choice of turbine type, number and arrangement can be selected. This software is a useful tool for beginner users to acquaint with equipment of hydro power plants, the applications and limitations of different type of hydraulic turbines. TURBNPRO software includes several types of turbine such as Francis turbines (vertical and horizontal axis, spiral case, semi-spiral case and flume type intakes, straight and elbow draft tubes), axial/propeller turbines (Kaplan, adjustable blade or adjustable gate regulation capabilities, spiral case, semi-spiral case and flume type intakes on conventional vertical units, tubular, pit type or bulb type horizontal arrangements) and Pelton Turbines (Vertical and horizontal axis, 1 to 6 jet designs) [26], [27]. As the user enters information, 10 options will be displayed with different diameters and speeds. The best option is usually the first one that has the lowest runner diameter and the highest speed. Selecting high specific speed of a given head would result in choosing a smaller turbine and generator which can save capital cost. Increase in drilling depth would lead to an increase in cost. The speed selection completely depends on the values of electrical energy, plant factor, economic analysis and comparison between higher speed costs and more drilling depth cost [28], [29].
Considering introduced softwares, the best choice for selecting and designing hydro power turbine is TURBNPRO. So, the reliability rate of this software is very important. The hydraulic performance and dimension database used in TURBNPRO is based on accumulated working experience with the actual turbine model designs characteristics of a number of turbine manufacturers including those of Voith, Allis Chalmers, S.M.Smith, Baldwin Lima Hamilton, Bouvier, Ebara, Neyrpic and others. Empirical data and equations are used to establish other turbine characteristics such as runaway speed, hydraulic thrusts, dimensions, etc. [26]. Furthermore, TURBNPRO software Manual is not included this basic empirical data and equations, therefore the best empirical equations have been found in this research. The reliability of these empirical equations has been checked by comparing their results with actual hydro power plant. This paper consists of mathematical (using empirical equation) and software methods results compared with actual value. Therefore, deviation of mathematical and software results from actual parameters could be calculated. This paper is based on Francis turbine, as this turbine has been used in many hydro power plants. The actual values were extracted from 6 under operation hydro power plant: Maroon, Abbaspour II, Masjid Suleiman, Dez, Karkheh, and the Karun III (located in Khuzestan Province, Iran).

\section{MATHEMATICAL METHOD}

Since there are several special equations for calculating the speed, runner diameter, dimensions of draft tube and spiral case for Francis turbine, it is absolutely necessary to analyze all of them and select the appropriate ones. After studying all accessible references and comparing their results with the actual values, equations of this paper have been selected.

Construction of hydro power plant and selection of hydro turbine are based on calculation of output power. It is necessary to consider head range and flow rate (or discharge) in order to determine the amount of installed capacity. Therefore, power available for the turbine is given by [30], [31]:

$$
P=9.8 \eta Q_{d} h_{d}
$$

where $h_{d}$ is design head in meter, $Q_{d}$ is design discharge in cubic meter per second, $P$ is nominal power in kilowatt and $\eta$ is the plant efficiency. In this research, the efficiency has been considered about 92 percent. Estimating the annual plant generation is necessary to optimize plant capacity. River flow has daily, seasonal and annual rainfall fluctuations. These fluctuations cause difficult estimation of plant power generation. Thus to resolve this problem, the fluctuation of river flow is explained by flow duration curve. The flow duration curve method is not used for a project with important changing in reservoir level except the specified reservoir level is considered in the calculation [30], [32]. Studying about flow duration curve is an initial step used to select the best turbine type, number and arrangement. Therefore this research is based on head and flow design which are selected after flow duration studying. 
In comparison with other parameters in hydro power plant, specific speed is the most important parameter, as the calculation of equipment dimension is based on it. Low specific speeds and high specific speed are concerned with high heads and low heads respectively [29]. It is easy to find several equations for specific speed in various references, but the best and the most accurate mathematical method is as follows. In this method, experimental specific speed $\left(n_{s}^{\prime}\right)$ can be calculated by using economic analysis or the following equations [29].

$$
\begin{array}{cc}
n_{s}^{\prime}=\frac{2334}{\sqrt{h_{d}}} & h_{d}>27 m \\
n_{s}^{\prime}=\frac{2702}{\sqrt{h_{d}}} & h_{d}<27 m
\end{array}
$$

where $h_{d}$ is design head in meter. The experimental rotational speed $(n$ ') is calculated after estimating experimental specific speed [29].

$$
n^{\prime}=\frac{n_{s}^{\prime} h_{d}^{1.25}}{P^{0.5}}
$$

where $h_{d}$ is design head in meter, $P$ is nominal power in kilowatt for full discharge and design head, $n$ ' is experimental rotational speed in revolutions per minute $(\mathrm{rpm})$. The rotational speed or design speed $(n)$ is calculated on the basis of experimental rotational speed. It is necessary to calculate the number of poles in order to finalize the value of rotational speed. Therefore, the obtained value of $n$ ' in equation (4) would be replaced by the value of $n$ in equation (5) [28], [29].

$$
n=\frac{120 f}{N_{p o l}}
$$

where $n$ is rotational speed in revolutions per minute $(\mathrm{rpm}), f$ is frequency in Hertz and $N_{p o l}$ is number of poles. The nearest rotational speed to the design speed is selected as a subject to the following consideration: [28], [29]. a) The number of generator poles usually is selected a multiple of two or four, but a multiple of four is preferred. b) When variation of head (Maximum head minus Minimum head) is lower than 10 percent of design head variation, the subsequent greater speed will be selected. When variation of head is greater than 10 percent of design head variation, the subsequent lower speed will be recommended.

After selecting the number of poles, the rotational speed would be calculated again using equation (5). Therefore, design specific speed is given by:

$$
n_{s}=\frac{n P^{0.5}}{h_{d}^{1.25}}
$$

where $n$ speed is in rpm, $p$ is nominal power in kilowatt and $h_{d}$ is design head in meter. Note that speed may be limited by mechanical design, cavitation range, vibrations, maximum efficiency drop and overall efficiency losses, also the unit of $n_{s}^{\prime}$ and $n_{s}$ are same.

The actual prototype runner size is determined by the manufacturer in accordance with model tests and design criteria; while in academic and consultant utilization, the engineers should rely on available empirical equations and commercial software. De Siervo and de Leva proposed the following equation for academic purposes. Therefore, discharge diameter is given by (Fig. 1) [1], [28], [29]:

$$
D_{3}=84.5 K_{u} \frac{\sqrt{h_{d}}}{n}
$$

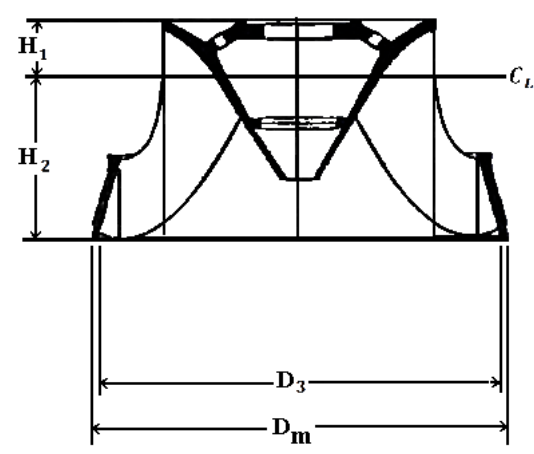

Fig. 1. Runner dimension [1].

Interpolation function, $K_{u}$, is calculated by the following equation [1], [28], [29]:

$$
K_{u}=0.31+2.5 \times 10^{-3} n_{s}
$$

In these two equations, $n_{s}$ is specific speed and $h_{d}$ is design head in meter. Other dimensions of turbine may be obtained in function of $n_{s}$ and $D_{3}$.

The spiral case is used in units with heads exceeding 30 meters. The manufacturer selects the dimensions details in accordance with their own design criteria and specification restrictions of spiral case velocity or penstock size [28], [29]. The main dimensions of the spiral case indicated in Fig. (2) would be obtained in following equation [1], [29]:

$$
\begin{gathered}
A=\left(1.2-\frac{19.56}{n_{s}}\right) D_{3} \\
B=\left(1.1+\frac{54.8}{n_{s}}\right) D_{3} \\
C=\left(1.32+\frac{49.25}{n_{s}}\right) D_{3} \\
D=\left(1.5+\frac{48.8}{n_{s}}\right) D_{3} \\
E=\left(0.98+\frac{63.6}{n_{s}}\right) D_{3}
\end{gathered}
$$

As determining an efficiency warranty, the manufacturer considers the draft tube as a part of the turbine, because it is 
difficult to measure the net effective head or pressure at the discharge diameter of the runner $\left(D_{3}\right)$. Therefore, the draft tube shape and dimensions is based on the limitations of the specifications and existing structure. For large units, it is recommended to use elbow tube, because excavation would be decreased.

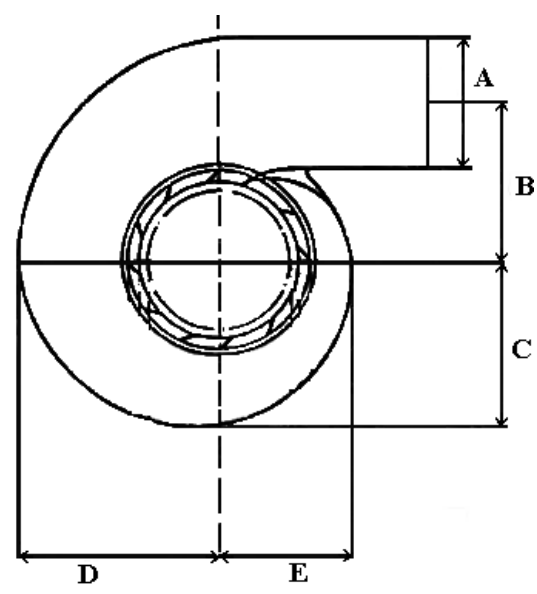

Fig. 2. Main spiral case dimension [1].

The draft tube size is directly determined by the size of runner and specific speed [1], [28], [29]. The main dimensions of the draft tube indicated in Fig. 3 would be obtained in following equation [1], [29]:

$$
\begin{gathered}
R=\left(1.6-\frac{0.0013}{n_{s}}\right) D_{3} \\
S=\left[n_{s} /\left(-9.28+0.25 n_{s}\right)\right] D_{3} \\
T=\left(1.5+0.00019 n_{s}\right) D_{3} \\
V=\left(1.1+\frac{53.7}{n_{s}}\right) D_{3} \\
U=\left(0.51-0.0007 n_{s}\right) D_{3}
\end{gathered}
$$

Main shaft of turbine is manufactured from forged carbon or alloy steel in high temperature. Single or multiple forged components may be used which are supplied with flanged coupling. Hollow bored is recommended for the shafts with more than $0.4 \mathrm{~m}$ in diameter. There are size limitations of a forging such as the capacity of available equipment for heating, handling and forging. The diameter of the shaft can be estimated from the following equation [29]:

$$
D_{s}=0.1042\left(\frac{P}{n}\right)^{\frac{1}{3}}
$$

where, $D_{s}$ is shaft diameter in meter, $P$ is nominal power in kilowatt and $n$ is design rotational speed in rpm.

When the speed rises more than rated speed, speed rise is occurred. In this condition the generator is operated at rated speed and the turbine is operated under governor control, suddenly, generator load becomes completely disconnected.
In speed rising conditions the turbine system has great vibration, so it is necessary to design turbine and generator to overcome speed rise. To avoid vibration damage, it must be kept the speed rise lower than 60 percent, about 35 to 45 percent.

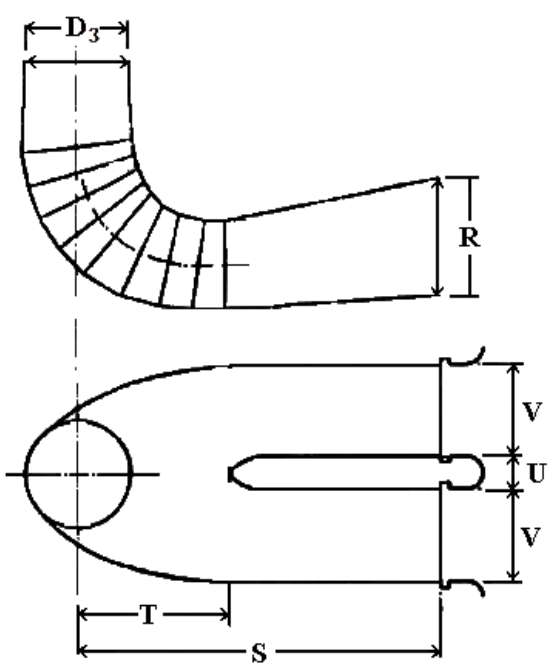

Fig. 3. Main draft tube dimension [1].

Conversely, when unit is at full gate, the governor is not working and the generator is disconnected from the system, runaway speed is occurred. Vibrations in the design of turbines and generators in several manufactures are different, so there are various equations of runaway speed [28], [29]. In this research the runaway speed would be obtained from following equation [1]:

$$
n_{r}=\left(1.52+1.52 \times 10^{-3} n_{s}\right) n
$$

where $n$ and $n_{s}$ are the speed and specific speed, respectively.

Cavitation commonly occurs in hydroelectric turbines, generally appearing around guide vanes, wicket gates, turbine runner, and in the draft tube. To resolve this problem, dangers level or suction head $\left(H_{s}\right)$ should be estimated. The recommended suction head was established by Thoma number. It is the most important parameter that describes cavitation in hydraulic turbine. Thoma number and $H_{s}$ are calculated as follows [29], [33], [34]:

$$
\begin{gathered}
\sigma=\frac{n_{s}^{1.64}}{50327} \\
H_{s}=h_{b}-\left(\frac{L}{900}+1.5\right)-\sigma \times h_{d}
\end{gathered}
$$

where, $L$ is site elevation in meter, $h_{b}$ is barometric pressure height in meter, $\sigma$ is cavitation coefficient and $h_{d}$ is design head in meter. Note that turbine is located $0.3 \mathrm{~m}$ below the $H_{s}$ level. This margin value is used to consider the variation of atmospheric pressure [22].

To estimate the weight of Francis turbine, several equations were suggested in the various references. In comparison with actual value, the following equation has minimum errors. Firstly, equivalent diameter $\left(D_{m}\right)$ is calculated (Fig. 1) [28], [29]. 
$D_{m}=\left(-5 \times 10^{-8} n_{s}^{3}+0.0054 \times 10^{-2} n_{s}^{2}-1.5853 \times 10^{-2} n_{s}+2.5018\right) D_{3}$

$$
57 \leq n_{s} \leq 225
$$

$D_{m}=\left(-9 \times 10^{-10} n_{s}^{3}+10^{-6} n_{s}^{2}-0.0478 \times 10^{-2} n_{s}+1.164\right) D_{3}$

$$
225<n_{s} \leq 450
$$

After that runner weight is given by [29]:

$$
G=0.607 D_{m}^{2.75}
$$

In this equation, $G$ is runner weight in ton.

\section{RESULTS}

Table I shows the head, discharge, speed, specific speed and nominal power of six plants, Maroon (2004), Dez (1963), Abbaspour II (2004), Masjid Suleiman (2003), Karkheh (2002) and Karun III (2004), located in Khuzestan Province, Iran. In this table, the value of $n_{s}$ has been calculated based on 92 percent efficiency. This assumption leads to small difference between actual values and calculated values of specific speed.

TABLE I: HeAd, Discharge, SPEED, SPECIFIC SPEED AND NOMINAL POWER IN SIX HYDRO POWER PLANTS

\begin{tabular}{|l|l|l|l|l|l|}
\hline \multicolumn{2}{|c|}{ IN SIX HYDRO POWER PLANTS } \\
\hline Maroon & 121 & 70 & $\begin{array}{l}\text { Discharge } \\
\left(\mathrm{m}^{3} / \mathrm{s}\right)\end{array}$ & $\begin{array}{l}\text { Speed } \\
(\mathrm{rpm})\end{array}$ & $\begin{array}{l}n_{s} \\
(M W)\end{array}$ \\
\hline Abbaspour II & 150 & 187.5 & 187.5 & 179.9 & 253.68 \\
\hline Karun III & 161 & 172 & 187.5 & 190.7 & 249.77 \\
\hline $\begin{array}{l}\text { Masjid } \\
\text { Suleiman }\end{array}$ & 140 & 190 & 187.5 & 133.45 & 239.92 \\
\hline Karkheh & 93 & 158.42 & 150 & 189.39 & 132.89 \\
\hline Dez & 152 & 59.2 & 250 & 163.4 & 81.16 \\
\hline
\end{tabular}

Calculation of mathematical model is based on the information gathered from six hydro power plants. As design problems and economic studies have been considered, in power plants such as Karkheh, Dez and Maroon, the selected speed in installed plant is less than the calculated amount. Therefore, in this paper real installed speed was utilized [35]-[40]. All parameters in TURBNPRO software and mathematical method were calculated separately. The differences between software and mathematical parameters with actual parameters have been calculated to be divided on actual parameters and then the average errors were calculated. Mathematical and software errors were shown in Fig. 4 and Fig. 5, respectively. According to Fig. 4 and Fig. 5, parameters such as $\mathrm{R}, \mathrm{S}, \mathrm{S}-\mathrm{T}$ and $2 \mathrm{~V}+\mathrm{U}$ have similar error values in both mathematical and software methods.

It is clear that these four parameters have similar equations for mathematical and software methods. But other parameters have different errors in two methods. The value of software errors in parameters such as Runaway Speed, Runner Diameter, Shaft Diameter, A and D are smaller than mathematical errors. These errors are smaller than 5 percent. Therefore, in these five parameters, software method is more reliable. Software error of Runner Weight is smaller than mathematical error, while it is larger than 5 percent. Although software error of $\sigma$ is larger than mathematical error, this error is negligible. In $\mathrm{B}, \mathrm{C}$ and $\mathrm{E}$ parameters, the mathematical errors are smaller than software errors. Therefore, mathematical errors in these parameters are more reliable. Note that the error value of E parameter is too small to be remarkable in mathematical model.

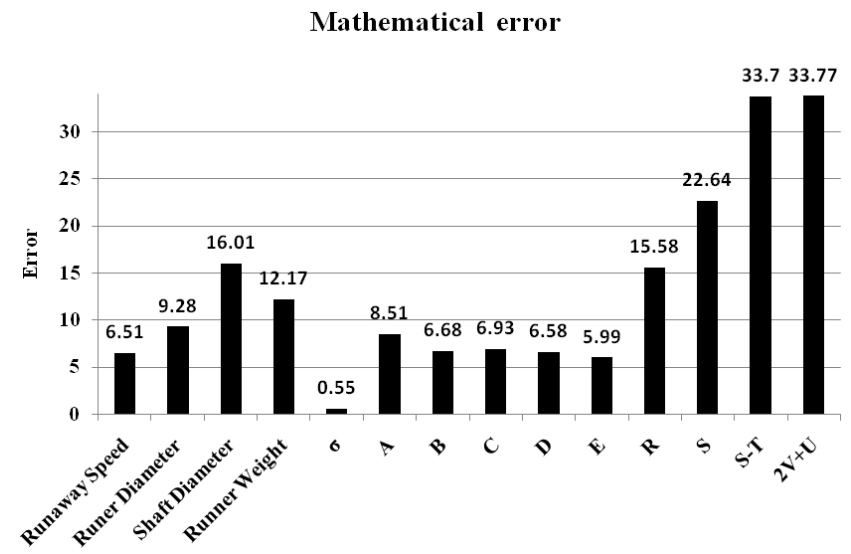

Fig. 4. Mathematical error in different parameters.

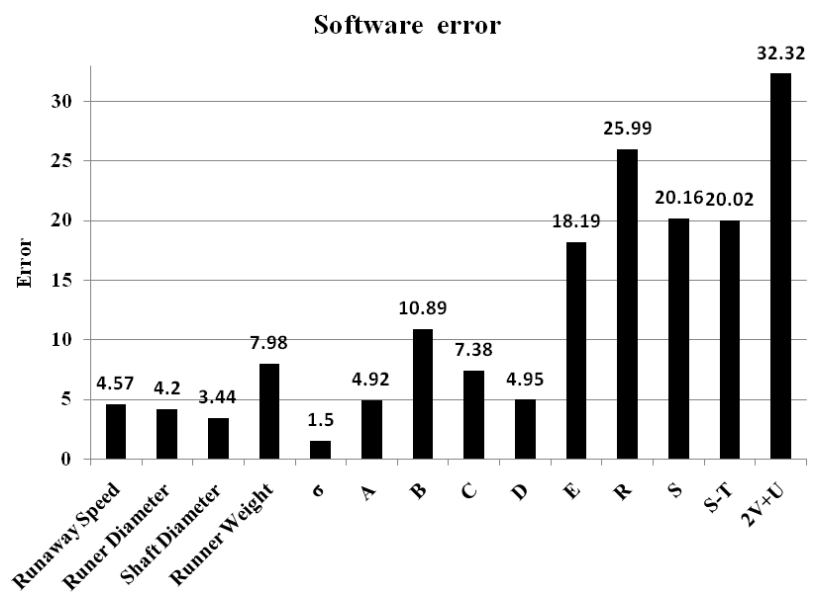

Fig. 5. Software error in different parameters.

The calculation errors show that only 6 parameters in software method and 4 parameters in mathematical method among 14 parameters have reliable results. These parameters are Runaway Speed, Runner Diameter, Shaft Diameter, A, D and $\sigma$ in software method and $\mathrm{B}, \mathrm{C}, \mathrm{E}$ and $\sigma$ in mathematical method. Therefore, it's not possible to confirm all parameters calculated with mathematical or software methods.

\section{CONCLUSION}

This paper introduced result reliability of TURBNPRO software and mathematical method for Francis turbine. Results were analyzed and compared with the actual values of six hydro power plants; known as Maroon, Abbaspour II, Dez, Masjid Suleiman, Karkheh and Karun III. Since information of hydro power plants is not usually released, research is based on available information of this 6 hydro power plant.

Comparing average mathematical and software errors with the actual values indicated that only 6 parameters in software method and 4 parameters in mathematical method among 14 parameters have reliable results. Runaway speed, runner 
diameter, shaft diameter, $\mathrm{A}, \mathrm{D}$ and $\sigma$ have reliable results in software method and $\mathrm{B}, \mathrm{C}, \mathrm{E}$ and $\sigma$ have reliable results in mathematical method. Therefore all parameters calculated in software or mathematical methods are not confirmable. Regarding to above information, the database used in TRBNPRO is based on accumulated characteristics of some turbine manufacturers for hydraulic performance and dimension. For other turbine characteristics empirical data and equations are used. It is necessary to mention that mathematical method is used empirical equations too. Existing accordance of 6 parameters among 14 parameters between actual and software method values demonstrated that they have used same equations. Furthermore, considering using empirical equations in mathematical method, only 4 parameters among 14 parameters have the same equations. Therefore remaining parameters in software and mathematical method are used only for initial estimations.

Note that in this paper the reliability of Francis turbine was considered and other turbines like Pelton, Kaplan etc. should be considered in next researches, so general approval or disapproval of TURBNPRO result reliability cannot be deduced by this research.

\section{REFERENCES}

[1] F. de Siervo and F. de Leva, "Modern trends in selecting and designing Francis turbines," Water Power \& Dam Construction, vol. 28, no. 8 , pp. 28-35, 1976.

[2] F. de Siervos and F. de Leva, "Modern trend in selecting and designing kaplan turbines (part one)," Water Power \& Dam Construction, vol. 29 pp. 51-56, 1977.

[3] F. de Siervos and F. de Leva, "Modern trend in selecting and designing kaplan turbines (part two)," Water Power \& Dam Constructions, vol. 30, pp. 51-57, 1978.

[4] F. de Siervos and F. de Leva, "Modern trend in selecting and designing pelton turbines," Water Power \& Dam Constructions, vol. 30, pp. 40-47, 1978.

[5] F. Schweiger and J. Gregori, "Developments in the design of Kaplan Turbines," Water Power \& Dam Constructions, vol. 39, no. 11, pp. 16-20, November 1987.

[6] J. L. Gordon, "A new approach to turbine speed," Water Power \& Dam Constructions, vol. 42, no. 8, pp. 39-46, August 1990.

[7] M. G. Harding, "Turbine selection for micro-hydropower stations in developing countries," College of Engineering and Technology Brigham Young University, Provo, Utah, United States, 1995.

[8] M. Sallaberger, C. Michaud, H. Born, S. Winkler, and M. Peron, "Design and manufacturing of francis runners for rehabilitation projects," Report of VA TECH Hydro, Company, 2001.

[9] M. N. Kyaw, N. P. Win, M. W. Khin, E. C. Ei, W. H. San et al., "Basic design of pelton wheel turbine," Government Technological College Meiktila, Department of Mechanical Engineering, Myanmar, 2006.

[10] A. Nourbakhsh, O. S. Razavi, H. Khodabakhsh, and A. Mehrabadi, "New approach for hydraulic design of francis runner based on empirical correlations," in Proc. International Conference on Small Hydropower, Hydra Sri Lanka, 2007.

[11] V. Soni, A. Roghelia, J. Deai, and V. Chauhan, "Design development of optimum draft tube for high head francis turbine using CFD," in Proc. the $37^{\text {th }}$ National International Conference on Fluid Mechanics and Fluid Power, Madras, Chennai, India, 2010.

[12] R. B. F. Albuquerque and W. Oliveira, "Conceptual design optimization of francis turbines," in Proc. $21^{\text {st }}$ Brazilian Congress of Mechanical Engineering, Natal, RN, Brazil, 2011.

[13] J. Obrovsky, H. Krausova, J. Spidla, and J. Zouhar, "Development of high specific speed francis turbine for low head HPP," Engineering Mechanics, vol. 20, no, 2, pp. 139-148, 2013.

[14] B. A. Nasir, "Design of high efficiency cross-flow turbine for hydro-power plant," International Journal of Engineering and Advanced Technology (IJEAT), vol. 2, issue 3, pp. 2249-8958, 2013.

[15] I. F. Odesola and J. I. Oririabre, "Development of a 5 KW Francis turbine runner using computation fluid dynamics," An International Multidisciplinary Journal, vol. 7, no. 3, pp. 178-195, 2013.
[16] B. A. Nasir, "Design of micro-hydro - electric power station," International Journal of Engineering and Advanced Technology, vol. 2, issue 5, pp. 39-47, 2013.

[17] Brochure on Hydra-HP. (2001). European atlas of small scale hydropower resources. Institute of Hydrology, Wallingford, United Kingdom. [Online]. Available: http://www.nerc-wallingford.ac.uk/ih/www/products/pdf/ hydra.pdf

[18] A. Kumar, G. Rees, and T. K. Raghuvanshi. (2002). Small hydropower assessment - A solution through hydra-HP software. Power Workshop: Map India. [Online]. Available: http://www.gisdevelopment.net/application/utility/power/utilityp0009 .htm

[19] User Manual for IMP5.0 (Integrated Method for Power Analysis), Natural Resources Canada, February 2004.

[20] IMP Software. (2004). Small Hydro International Gateway, IEA small hydro, Canada. [Online]. Available: http://www.small-hydro.com/Programs/Policy,-Regulations---Plannin g/IMP-Software.aspx

[21] A. Conner and J. Francfort, "U.S. hydropower resource assessment for Alaska," Idaho National Engineering and Environmental Laboratory, Renewable Energy Products Department, 1997.

[22] J. E. Francfort, S. D. Matthews, and B. N. Rinehart, "User manual for hydro power evaluation software," U.S. Department of Energy Idaho Operations Office, June 2002.

[23] Natural Resources Canada, Clean Energy Decision Support Center. (2004). Clean Energy Project Analysis: RETScreen engineering \& cases textbook, small hydro project analysis chapter. [Online]. Available: http://www.Retscreen.net

[24] J. L. Gordon and P. Eng, "Turbine selection for small low-head hydro developments," presented at Innovative Small Hydro Technologies Conference Workshop, Buffalo, New York, U.S.A, 2003.

[25] J. Alterach, A. Elli, and M. Vergata, "D5.3 customized tools (software) Vapidro ASTE 4.0 user guide, work package 5-common strategies to improve SHP implementation," Version01, the South-East Europe Transnational Cooperation Program, 2012.

[26] Hydro Info Systems, “TURBNPRO version 3 user's guide," USA, 2007.

[27] Hydro info system, USA. (2011). TURBNPPRO software. [Online]. Available: http://www.turbnpro.com

[28] E. Mosonyi, "Water power development," High Head Power Plant, Akademiai Kiado, Budapest, 1991.

[29] USBR, "Selecting of reaction turbine," United States Department of the Interior Bureau of reclamation, 1976.

[30] The Guide to Hydro Power Mechanical Design, American Society of Mechanical Engineers (ASME) Hydro Power Technical Committee, HCI Publications, 1997.

[31] Gutheri and Brown, "Hydroelectric engineering practice," CBS Publication \& Distributors Delhi in Agreement with Blakie \& Sons Ltd, London, 1970

[32] C. Penche, Layman's Handbook on How to Develop a Small Hydro Site, 2nd ed. Commission of the European Communities, 1998.

[33] A. Kjolle, "Hydro power in Norway, mechanical equipment," Norwegian University of Science and Technology, 2001.

[34] F. Avellan, "Introduction to cavitations in hydraulic machinery," in Proc. the 6th International Conference on Hydraulic Machinery and Hydrodynamics, Romania, October 21-22, 2004.

[35] Maroon Tender Documents, Khuzestan Water \& Power Authority, Khuzestan Province, Iran, 2004.

[36] Abbaspour-II Tender Documents, Khuzestan Water \& Power Authority, Khuzestan Province, Iran, 2004.

[37] Karun-III Tender Documents, Iran Water \& Power Resources Development Co., Khuzestan Province, Iran, 2004.

[38] Masjid Suleiman Tender Documents, Iran Water \& Power Resources Development Co., Khuzestan Province, Iran, 2003.

[39] Karkheh Tender Documents, Iran Water \& Power Resources Development Co., Khuzestan Province, Iran, 2002.

[40] Dez. Tender Documents, Khuzestan Water \& Power Authority, Khuzestan Province, Iran, 1963.

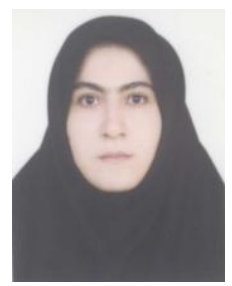

Moona Mohammadi got her bachelor of mechanica engineering from Tehran University of Science and Technology and her master of mechanical engineering from Shiraz University.

She works in Kuzestan Water \& Power Authority (KWPA) as an expert of hydro power turbine, Ahvaz, Iran. A book entitled "Governer of hydro power turbines" and 13 publications in conferences and 
journals are her research activities in recent years. Some of her published papers are: "Analysis of cooling air jacket and air distributor in a co-current spray dryer," Iranian Journal of Science and Technology, 2009; "Simulation of spray dryer with cooling air jacket by computational fluid dynamics," in Proc. the Second International Conference on Thermal Engineering Theory and Applications, Al-Ain, UAE, 2006; "Optimizing hydro power turbines in order to secure the passage of fishes in Khuzestan province," Journal of Applied and Computational Mechanics, 2014.

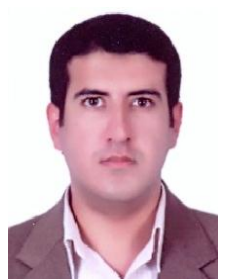

Mohammadreza Mohammadi was born in 1987 in Ahvaz, Iran. He got his bachelor of mechanical engineering from IAU Ahvaz, Iran, in 2005 and his master degree of mechanical engineering degree from University of Sistan and Baluchestan, Iran, in Febraury 2014

Since Dec. 2013, he has been working in Iranian National Company as a manager of operation and maitainance, Bushehr, Iran. He previously worked in the Optimization Laboratory of Mechanical Enginnering in University of Sistan and Baluchestan as a reaserch assistant. Mohammadi has 15 pulished papers in journals and conferences. Some of his papers are : 1). "Optimization of $60 \mathrm{KW}$ wind turbine blade using genetic algorithm," in Proc. $3^{\text {rd }}$ International Conference on Emerging Trends in Energy Conservation, Tehran, Iran, 2014. 2). "Optimizing hydro power turbines in order to secure the passage of fishes in Khuzestan province," Journal of Applied and Computational Mechanics, 2014. 3). "Potential of Jet stream in Iran and capacity of its energy generation," in Proc. The $22^{\text {nd }}$ Annual International Conference on Mechanical Engineering, Shahid Chamran University of Ahvaz, Mechanical Engineering April 2014, Ahvaz, Iran.

Mr. Mohammadi was selected among tens of thousands participants in National Iranian Gas Company entrance examination in 2013. He also won the Best Paper Award for his paper in $3^{\text {rd }}$ International Conference on Emerging Trends in Energy Conservation, Tehran, Iran 2014.

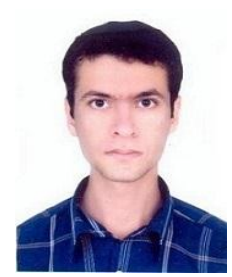

Alireza Mohammadi was born in 1983 in Ahvaz, Iran. He got his bachelor and master degrees of mechanical engineering from IAU Ahvaz in 2007 and 2011 respectively.

$\mathrm{He}$ is a lecturer in University of Applied Science and Technolgy, Deylam, Iran. He was previously a lecturer in Payame Nour University of Shoushtar and Abadan. Mohammadi has 11 publications in conferences and journals. Some of his publications are: 1). "Optimizing hydro power turbines in order to secure the passage of fishes in Khuzestan province, Journal of Applied and Computational Mechanics, 2014. 2). "Tension analysis of $25 \mathrm{KW}$ wind turbine blade," in Proc. First International Conference on Emerging Trends in Energy Conservation, Tehran, Iran, 2012. 3). "Potential of Jet stream in Iran and capacity of its energy generation," in Proc. the $22^{\text {nd }}$ Annual International Conference on Mechanical Engineering, Shahid Chamran University of Ahvaz, April 2014, Ahvaz, Iran.

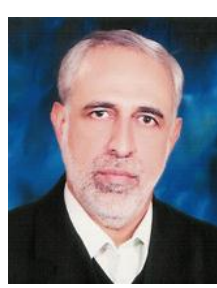

Said Farahat received the B.S. degree in mechanical engineering from Sharif University of Technology in 1978 and M.S. degree in computer science from Sharif University of Technology in 1983. He had also received the M.S. degree in mechanical engineering from University of Concordia in 1987 and Ph.D. degree in mechanical engineering (computer automated and integrated design) from University of Ottawa in 1999.

$\mathrm{He}$ is currently a full professor in the Mechanical Engineering Department of University of Sistan and Baluchestan.

His research interests are in the field of control, optimization and numerical analysis. 

Wind Energy 
